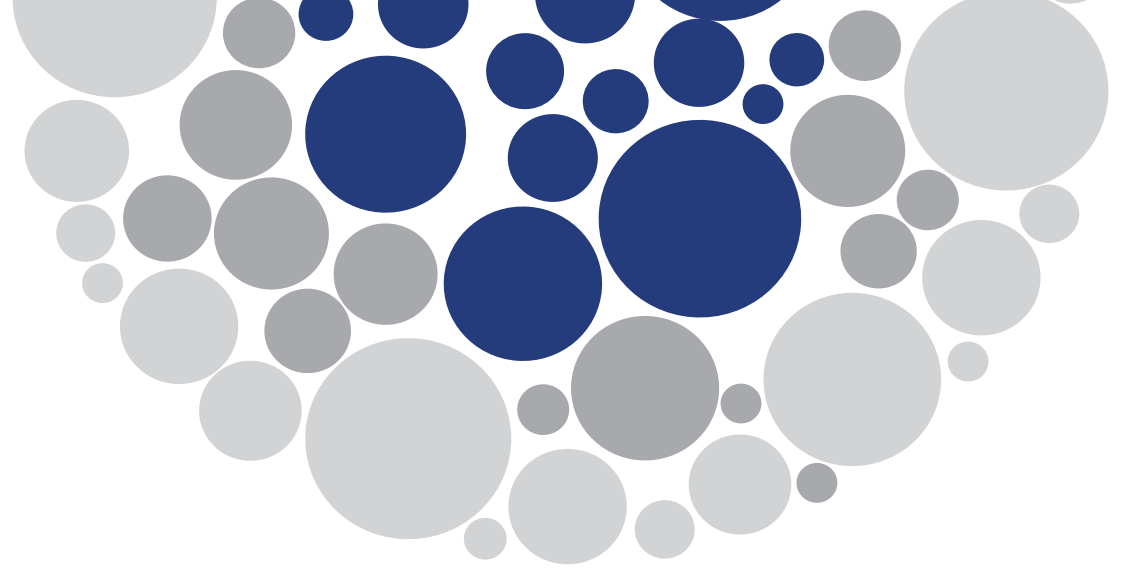

\title{
A Conferência de Estocolmo e as posturas políticas diante da questão ambiental
}

\author{
Arthur Soffiatia \\ a Universidade Federal Fluminense, RJ, Brasil. E-mail: as-netto@uol.com.br
}

Se a Conferência de Estocolmo, realizada em 1972 pela Organização das Nações Unidas (ONU), não conseguiu um consenso dos Estados-membros quanto ao enfrentamento da crise ambiental global que já vinha sendo percebida e que motivou a histórica reunião, ao menos pode-se tomá-la como marco para o reposicionamento político de liberais, socialistas e anarquistas ou mesmo para a reafirmação de suas posturas políticas tradicionais. Para começar a discussão, não podemos esperar tipos ideais ao estilo de Max Weber. Aliás, esse sociólogo só construiu tipos ideais para, a partir deles, buscar apreender a complexidade de cada postura política.

Para compreender os posicionamentos político-filosóficos dos atores sociais que emergiram da Conferência de Estocolmo, cumpre retornar ao século XVIII, ao Iluminismo, à Revolução Francesa. Simplificando, podemos dizer que, na transição do século XVIII para o XIX, três tendências se afirmaram: o liberalismo, o socialismo e o anarquismo. A crise ambiental global está estava em marcha desde o século XV com a expansão europeia. No fim do século XVIII, ela se aprofundou com a Revolução Industrial, aliás tomada superficialmente como marco para a crise. Adam Smith e François Quesnay afirmaram o liberalismo ao propor o desenvolvimento ou o progresso das nações por dois caminhos distintos. Smith enfatizou o industrialismo, fundando a escola de desenvolvimento, que ficou conhecida como Escola Clássica. Quesnay, por sua vez, fundou a Escola Fisiocrata, que pleiteava o desenvolvimento tendo atividades rurais como motores. 
Embora os Estados Unidos priorizassem o desenvolvimento pela via industrial, a Escola Fisiocrata influenciou o movimento de proteção à natureza exatamente contra um crescimento econômico que se revelou predatório. Catherine Larrère mostrou como esse movimento se dividiu em duas tendências que pleiteavam a criação de áreas para a proteção de amostras significativas ou de monumentos naturais. Seriam os Parques. Para nós, o conceito que se firmou na legislação é o de Unidade de Conservação. Nos Estados Unidos, uma corrente pleiteava a criação de parques abertos à visitação, enquanto a outra pretendia que tais Parques fossem fechados para a proteção integral da natureza. O movimento de proteção da natureza nos Estados Unidos divide-se, assim, em conservacionismo e preservacionismo, correntes que se manifestariam em todo o mundo ocidental primeiro e ocidentalizado posteriormente (LARRÈRE, 2008). O conservacionismo insere-se perfeitamente no liberalismo ao propor a proteção de áreas de especial importância ambiental e cênica para visitação que contribua para a educação. Do lado de fora delas, o crescimento econômico pode continuar desenfreado. Já o preservacionismo pleiteia a proteção de áreas ambientalmente importantes para a proteção da vida selvagem, sem a visitação de humanos. Ela pode combinar-se com o liberalismo, na medida em que o crescimento econômico destrutivo atue fora de tais áreas protegidas. Assim, existe nessa postura um viés saudosista de uma natureza virgem.

No Brasil, a Escola Clássica não exerceu influência expressiva no século XIX. Podemos dizer que ela se manifestou no projeto industrialista de Irineu Evangelista de Souza, o Barão de Mauá. A Escola Fisiocrata, ao contrário, influenciou significativamente os jovens ricos que saíam do país para estudar em Coimbra ou em Paris. Explica-se: o Brasil era dominado por uma economia rural rude e predatória, de um exponencialismo (examinaremos esse conceito adiante) exacerbado. Esses jovens ou já senhores, ao retornarem ao Brasil, passaram a defender o desenvolvimento do país pela via Rural, até porque o ruralismo predominava. Os nomes mais expressivos eram os de José Bonifácio e Joaquim Nabuco (PÁDUA, 2002). Essa tradicional linha liberal de proteção à natureza ganhou adeptos célebres, como André Rebouças, Euclides da Cunha, Alberto Torres e Luís Amaral, e desembocou na criação da Fundação Brasileira para a Conservação da Natureza, em 1958. Ela pleiteava a proteção de parcelas significativas de ambientes nativos em pontos estratégicos e, principalmente, a conservação da água.

Do Iluminismo e da Revolução Francesa também emerge o socialismo, que teve em Karl Marx e Friedrich Engels seus maiores representantes. Ambos mostraram os impactos do modo de produção capitalista nos humanos e na natureza (MARX; ENGELS, 1975; ENGELS, 1974). No geral, contudo, predominou neles a preocupação com a dimensão social. Prevalecia na época em que ambos viveram a crença em um humanismo exacerbado. De forma reducionista, entendeu-se que uma revolução comunista socializaria os meios de produção, mas não abdicaria do projeto de domínio da natureza em favor do homem. $\mathrm{Na}$ Revolução Russa de 1917, prevaleceu um projeto produtivista não muito distinto do projeto liberal de dominação da natureza. Mas o socialismo não se restringe ao marxismo, pois foram desenvolvidas propostas socialistas não marxistas.

Por fim, falta falar do anarquismo. No auge da Revolução Francesa, o socialista Robespierre acusava a oposição radical, representada pelo grupo liderado por Jacques Roux, de anarquista, emprestando a esse termo forte conotação negativa. No final de sua vida, Rousseau (1986) adotou postura análoga à do anarquismo em seu último livro. Como chamamos a atenção para a dificuldade de encontrar tipos puros, identificamos 
em Rousseau traços liberais, socialistas e anarquistas. O primeiro anarquista pensador a escrever dos impactos da economia sobre a natureza foi o norte-americano Henry David Thoreau (1817-1862) (THOREAU, 1984). Seu anarquismo, contudo, vinha contaminado pelo liberalismo radical, representado por um exacerbado individualismo e pela desobediência civil. O pensador anarquista que mais associou a questão social à ambiental foi, sem dúvida, o russo Peter Kropotkin (1842-1921).

Entre a Revolução Industrial e a Conferência de Estocolmo, as três correntes - liberalismo, socialismo e anarquismo - manifestaram-se na sua forma dura, sem preocupações maiores com os impactos de um desenvolvimento clássico ou fisiocrata sobre o meio natural. Pelo menos uma década antes da Conferência, representantes das três correntes - com as esperadas combinações entre elas - vinham já chamando a atenção para os efeitos de um crescimento veloz e desenfreado sobre a natureza. O liberalismo manifestava tal preocupação ao fundar o Clube de Roma em 1968, embora sua projeção tivesse ocorrido depois de 1972. Emergia uma nova questão. Durante a Conferência e depois dela, representantes da três correntes mantiveram suas posturas tradicionais, ou seja, continuaram a defender um crescimento exponencial, alegando que a questão ambiental era um movimento dos países ricos para congelar o desenvolvimento dos países pobres (liberais) ou um projeto da classe média desejosa de manter as desigualdades sociais ou de se rebelar contra o pagamento de impostos (socialistas e anarquistas). O exponencialismo é uma atitude que considera a natureza como um estoque de recursos para a economia e como lixeira para descarte de dejetos, podendo estar presente no liberalismo, socialismo e anarquismo.

A delegação brasileira na Conferência de Estocolmo foi presidida pelo diplomata João Augusto de Araújo Castro, que servira ao governo de João Goulart e à ditadura militar de 1964. Ele ilustra bem a dificuldade em se trabalhar com tipos ideais, pois serviu tanto a um governo socialista quanto a governos liberais reacionários. Contudo, embora liberal, ele tinha posições fortes, até certo ponto consideradas de esquerda. A postura da delegação na Conferência foi a de um marcado exponencialismo. Em um artigo, Araújo Castro assinala com clareza a posição que adotou em Estocolmo:

[...] na consideração dos problemas atinentes à preservação do meio humano, tende-se a colocar uma tônica demasiado forte nos perigos da poluição certamente graves para os países altamente industrializados, quando a maior parcela do planeta ainda vive num estágio de pré-contaminação ou, em outras palavras, ainda não teve a oportunidade de ser poluído. Duas terças partes da humanidade estão muito mais ameaçadas pela fome e pela penúria do que pelos males da poluição. Por isso mesmo, causam apreensões as recentes declarações do senhor McNamara - contraditadas pelo Brasil no Conselho Econômico Social - de que o Banco Mundial doravante não autorizará qualquer projeto de desenvolvimento econômico sem uma avaliação minuciosa de eventuais repercussões sobre o ambiente. É claro que os países em desenvolvimento não quererão incorrer nos mesmos erros em que incorreram os países altamente industrializados, mas é evidente que não poderíamos aceitar a ressurreição, em pleno século XX, da teoria do selvagem feliz, de Rousseau, que deu sabor e colorido a todo romantismo francês. "Não deixem acontecer com suas cidades o que aconteceu com Nova York". "Conservem suas belas praias". São frases essas constantemente marteladas nos tímpanos dos representantes dos países em desenvolvimento. Ora, esses países em desenvolvimento partem da premissa de que qualquer programa adequado para a preservação do meio humano deve ter em linha de conta os fatores básicos do desenvolvimento, já que o subdesenvolvimento representa, por si só, uma das piores formas de poluição do ambiente. (ARAÚJO CASTRO, 1972). 
Depois da Conferência, apareceram muitas vozes de marxistas condenando o movimento de proteção da natureza. O mais conhecido no Brasil foi o português João Bernardo, que publicou um manifesto antiecológico, mas muitas outras vozes se somaram à dele (BERNARDO, 1979; TIBALDI, 1980; FAIVRET; MISSIKA; WOLTON, 1980; SOUZA; AMARAL VIEIRA,1984; ALPHANDÉRY; BITOUN; DUPONT, 1992). O pronunciamento de um marxista também revelou resistência conservadora ao movimento de defesa do ambiente. Foi o de Gildo Magalhães:

Não há por que retrocedermos historicamente: o homem conquistará cada metro quadrado útil do planeta e depois irá ao espaço [...]; para minimizar os efeitos depressivos do capitalismo, é preciso ser antiecológico, inclusive é preciso exaurir todas as reservas de energia conhecidas o mais rapidamente possível, pois só assim serão gerados os recursos para descobrir novas fontes de energia, necessárias para nossa expansão. (MAGALHÃES, 1984).

Do lado anarquista no Brasil, Maurício Tragtenberg viu os movimentos de defesa do meio ambiente como manifestações pequeno-burguesas de pessoas que não queriam pagar impostos (TRAGTEMBERG, 1984).

Houve mudanças gradativas entre os liberais no pós-Conferência, e a mais expressiva foi a manifestada no Clube de Roma, já mencionado como uma das forças promotoras da Conferência. Tratava-se de uma associação de empresários que buscou a assessoria de estudiosos, encomendando-lhes livros, entre os quais o mais conhecido foi Limites do crescimento, mas não o único (MEADOWS et al., 1973; MESAROVIC; PESTEL, 1975).

Entre os socialistas, emergiu uma plêiade de pensadores que empreenderam uma crítica radical ao modo de produção capitalista não apenas na sua dimensão social, mas também em suas relações com a natureza. O preço pago por eles foi o banimento ou o autoafastamento dos partidos comunistas. Alguns nem pertenciam aos quadros de um partido; apenas revelavam postura progressista, o que facilitou a apresentação de suas obras. Os mais expressivos pensadores progressistas que incorporaram a questão ambiental de forma inovadora às suas reflexões foram Rudolf Bahro, Michel Bosquet (pseudônimo de André Gorz), Jean-Pierre Dupuy, Ivan Illich, Dominique Simonnet e Laura Conti (BAHRO, 1980; BOSQUET, 1976; DUPUY, 1980). No campo da economia, o novo paradigma irrompeu nos trabalhos de Schumacher, Georgescu-Roegen, Ignacy Sachs, Herman Daly e Richard Wilkinson, para só citar os mais conhecidos (SCHUMACHER, 1979; GEORGESCU-ROEGEN, 1971; SACHS, 1986a, 1986b; DALY, 1984; WILKINSON, 1974). Essa linha de pensamento ficou conhecida como ecologismo. Se cabem, neste escrito, posicionamentos pessoais, o autor deste texto filiou-se a essa linha de pronto, fascinado pelas reflexões de seus representantes, e pretendeu expressá-la na região em que vive por meio de pensamento, ação e escritos.

No anarquismo, os nomes mais representativos foram os de Murray Bookchin e Roberto Freire (BOOKCHIN, 1978; FREIRE, 1992).

Das três correntes anteriores e posteriores à Conferência de Estocolmo, o exponencialismo liberal e o socialista continuaram a vigorar. Na Conferência Rio-92, Fidel Castro ainda sustentava que a espécie mais ameaçada de extinção era o homem. João Almino escreveu artigos resistindo às propostas de incorporação da questão emergente ao socialismo ou buscando efetuar uma tipologia confusa das correntes ideológicas pós-Estocolmo (ALMINO, 1990, 2004). 
De forma difusa, sem nomes expressivos, o liberalismo resistiu a mudanças de pensamento, mas também avançou dentro da ONU, com a Comissão Brundtland. Promovendo audiências públicas em todo o mundo, a Comissão publicou, em 1987, o livro Nosso futuro comum, com a proposta de desenvolvimento sustentável ou simplesmente sustentabilidade (COMISSÃO MUNDIAL SOBRE MEIO AMBIENTE E DESENVOLVIMENTO, 1988). O autor deste trabalho esteve presente à audiência pública realizada em São Paulo e, sem saber com clareza sobre o que se discutia, ofereceu como contribuição um texto em que expressava suas convicções ecologistas, aliás incluído nas referências do livro. Mais uma vez, reforça-se a percepção de que não existem tipos ideais. O conceito de sustentabilidade é liberal, mas incorpora questões caras ao socialismo, como distribuição de renda, saneamento básico, redução das desigualdades sociais, direitos universais do cidadão etc. Tanto que desenvolvimento sustentável se tornou hoje um conceito vulgarizado pela direita e pela esquerda. O conceito norteou a Conferência Rio-92, Rio+20 e todas as conferências temáticas patrocinadas pela ONU. Na Rio+20, buscou-se em vão substituir o conceito de sustentabilidade pelo de economia verde. Cabe observar que, na Conferência Rio-92, a Cúpula dos Povos, reunindo tendências progressistas, efetuou cerradas críticas à proposta de desenvolvimento sustentável, porém o conceito acabou por triunfar.

Socialistas que não aceitavam mais a tradicional postura exponencialista e que repudiavam a postura liberal de desenvolvimento sustentável sem a devida crítica avançaram para a concepção de Justiça Ambiental, hoje um movimento com fortes alicerces no Brasil. Por outro lado, Michael Löwy formulou o ecossocialismo, que não se propagou tanto quanto Justiça justiça Ambientalambiental (LÖWY, 2014).

O quadro se torna mais complexo quando se consideram as combinações da questão ambiental com as diversas doutrinas religiosas e os movimentos feminista (ecofeminismo), de gênero e de raça; ainda mais se levarmos em conta que as posturas preservacionistas, conservacionistas e ecologistas perduram em nichos. $\mathrm{O}$ veganismo conserva muito do preservacionismo e é defendido por pessoas liberais e socialistas. O conservacionismo continua presente em orientações liberais que defendem a criação de unidades de conservação, por exemplo. Por outro lado, as teorias da Justiça Ambiental e do ecossocialismo não substituíram de todo o ecologismo do qual ambas derivam. O autor destas linhas ainda se insere parcialmente em tal tendência desde os anos de 1970, entendendo-a como a primeira utopia planetária até pouco tempo (SOFFIATI, 2007).

Mas deve-se reconhecer que o liberalismo está dando as cartas. Existe uma tendência liberal radical que se expandiu depois da queda da União Soviética e dos países socialistas europeus entre 1989-1991. Tal queda foi saudada como o fim da história e abriu caminho para o avanço do neoliberalismo (FUKUYAMA, 1992). O Estado de bem-estar social, que combinou liberalismo e socialismo, está sob o fogo cerrado do neoliberalismo. Contudo, as condições objetivas evidenciam cada vez mais que o Estado, mesmo no mundo liberal, não pode reduzir-se a dimensões mínimas. Com tanto problemas sociais, a pandemia causada pelo novo coronavírus (Sars-CoV-2) e a crise ambiental exigem o retorno de um Estado de bem-estar agora socioambiental.

\section{Referências}

ALMINO, J. Ideias de naturezas mortas. Jornal do Brasil, Rio de Janeiro, 11 nov. 1990.

ALMINO, J. Naturezas mortas. Rio de Janeiro: Francisco Alves, 2004. 
ALPHANDÉRY, P.; BITOUN, P.; DUPONT, Y. O equívoco ecológico: riscos políticos. São Paulo: Brasiliense, 1992.

ARAÚJO CASTRO, J. A. O congelamento do poder mundial. Revista Brasileira de Estudos Políticos, Belo Horizonte, n. 33, p. 7-30, 1972.

BAHRO, R. A alternativa: para uma crítica do socialismo real. Rio de Janeiro: Paz e Terra, 1980.

BERNARDO, J. O inimigo oculto: manifesto antiecológico. Lisboa: Afrontamento, 1979.

BOOKCHIN, M. Por una sociedad ecológica. Barcelona: Gustavo Gili, 1978.

BOSQUET, M. Ecologia e política. Lisboa: Notícias, 1976.

COMISSÃO MUNDIAL SOBRE MEIO AMBIENTE E DESENVOLVIMENTO. Nosso futuro comum. Rio de Janeiro: Fundação Getúlio Vargas, 1988.

DALY, H. A economia do século XXI. Porto Alegre: Mercado Aberto, 1984.

DUPUY, J.-P. Introdução à crítica da ecologia política. Rio de Janeiro: Civilização Brasileira, 1980.

ENGELS, F. O papel do trabalho na transformação do macaco em homem: dialéctica da natureza. Lisboa: Presença; Rio de Janeiro: Martins Fontes, 1974. (Data de cólofon).

FAIVRET, J.-P.; MISSIKA, J.-L.; WOLTON, D. L’Illusion écologique. Paris: Du Seuil, 1980.

FREIRE, R. A farsa ecológica. Rio de Janeiro: Guanabara Koogan, 1992.

FUKUYAMA, F. O fim da história e o último homem. Rio de Janeiro: Rocco, 1992.

GEORGESCU-ROEGEN, N. The entropy law and the economic process. Cambridge: Harvard, 1971.

LARRÈRE, C. Duas filosofias de proteção à natureza. In: SANTOS, A. C. Filosofia e natureza: debates, embates e conexões. Aracaju: Universidade Federal de Sergipe, 2008.

LÖWY, M. O que é o ecossocialismo. 2. ed. São Paulo: Cortez, 2014.

MAGALHÃES, G. A anti-ecologia necessária. Socialismo e Democracia, São Paulo, n. 1, 1984.

MARX, K.; ENGELS, F. Cartas sobre las ciencias de la naturaleza y las matemáticas. Barcelona: Anagrama, 1975.

MEADOWS, D. H. et al. Limites do crescimento. São Paulo: Perspectiva, 1973.

MESAROVIC, M.; PESTEL, E. Momento de decisão: o segundo informe ao Clube de Roma. Rio de Janeiro: Agir, 1975.

PÁDUA, J. A. Um sopro de destruição: pensamento político e crítica ambiental no Brasil escravista (1786-1888). Rio de Janeiro: Jorge Zahar, 2002.

ROUSSEAU, J.-J. Os devaneios do caminhante solitário. Brasília: EdUnB, 1986.

SACHS, I. Ecodesenvolvimento: crescer sem destruir. São Paulo: Vértice, 1986a.

SACHS, I. Espaços, tempos e estratégias do desenvolvimento. São Paulo: Vértice, 1986b.

SCHUMACHER, E. F. O negócio é ser pequeno. Rio de Janeiro: Zahar, 1979.

SOFFIATI, A. Ecologismo: a primeira utopia planetária. Morus: Utopia e Renascimento, Campinas, n. 4, 2007. SOUZA, A. B.; AMARAL VIEIRA, R. A. Poluição, alienação e ideologia. Rio de Janeiro: Achiamé, 1984. THOREAU, H. D. Walden ou a vida nos bosques. São Paulo: Global, 1984.

TIBALDI, E. Antiecologia. Barcelona: Anagrama, 1980.

TRAGTEMBERG, M. Ecologia versus capitalismo. Economia e Desenvolvimento, São Paulo, n. 2, 1984.

WILKINSON, R. Pobreza e progresso: um modelo ecológico de desenvolvimento econômico. Rio de Janeiro: Zahar, 1974.

SOBRE O AUTOR

Arthur Soffiati; SOFFIATI, A. Universidade Federal Fluminense (UFF). Professor Associado I da Universidade Federal Fluminense, em Campos dos Goytacazes (UFF/Campos). 